Running head: GLOBAL WELL-BEING AND ALTRUISM

1 This manuscript was accepted for publication in Psychological Science on December 20, 2020.

2

3

4

5

6

7

\title{
Global variation in subjective well-being predicts seven forms of altruism
}

\author{
Shawn A. Rhoads ${ }^{\mathrm{a}^{*}}$, Devon Gunter ${ }^{\mathrm{b}}$, Rebecca M. Ryan ${ }^{\mathrm{a}}$, \& Abigail A. Marsh ${ }^{\mathrm{a}^{*}}$ \\ a Department of Psychology, Georgetown University, $37^{\text {th }}$ \& O Streets N.W., Washington DC \\ 20057, USA \\ bepartment of Psychology, Harvard University, 31 Kirkland Avenue, Cambridge, MA, 02138, \\ USA
}

Correspondence to: Shawn A. Rhoads (r1209@georgetown.edu); 37 th $^{\text {th }}$ and O Streets NW,

White Gravenor 304; Washington, DC 20057

Acknowledgments: We thank Kathleen Neill for help compiling data.

Funding: This work was supported by a Kuno Award for Applied Social Sciences for the Social Good to A.A.M. and the National Science Foundation Graduate Research Fellowship Program Award to S.A.R.

Contributions: D.G., S.A.R., and A.A.M. gathered and organized the data. S.A.R. analyzed the data with input from R.M.R. S.A.R. wrote the manuscript. A.A.M. and R.M.R. revised the manuscript.

Data availability: The data and code presented in this manuscript are available on the Open

Science Framework at https://osf.io/qsdfp/

Conflicts of Interest: None declared. 
Abstract

26 The geographic prevalence of various altruistic behaviors (non-reciprocal acts that improve

27 others' welfare) is non-uniformly distributed. But whether this reflects variation in a

28 superordinate construct linked to national-level outcomes or cultural values is unknown. We

29 compiled data on seven altruistic behaviors across 48-152 nations, and found evidence that these

30 behaviors reflect a latent construct positively associated with national-level subjective well-being

31 (SWB) and individualist values, even controlling for national-level wealth, health, education, and

32 shared cultural history. Consistent with prior work, we found that SWB mediates the relationship

33 between two objective measures of well-being (wealth and health) and altruism $(\mathrm{N}=130)$.

34 Moreover, these indirect effects increase as individualist values increase within the subset of

35 countries $(\mathrm{N}=90)$ with available data. Together, results indicate that altruism increases when

36 resources and cultural values provide objective and subjective means for pursuing personally

37 meaningful goals, and that altruistic behaviors may be enhanced by societal changes that

38 promote well-being.

Keywords: altruism, prosocial behavior, subjective well-being, individualism

40 Significance Statement

41 We report the first evidence that seven objectively and subjectively measured altruistic behaviors

42 compiled from five distinct sources across 48-152 nations reflect a single latent construct that is

43 positively associated with national-level well-being and individualist cultural values. Consistent

44 with prior work in the United States, we find that global-scale variation in subjective well-being

45 partially mediates the relationship between two measures of objective well-being (wealth and

46 health) and altruism. Over and above this relationship, these identified partial indirect effects

47 increase as individualist values within a country increase. Our work supports theoretical

48 frameworks that position subjective well-being as a promotional factor for engaging in activities

49 that are pursued for their own sake and contribute to further enhancements in well-being. These

50 new insights suggest that when resources and cultural values provide the objective and subjective

51 means for pursuing individual goals, among the goals people become more inclined to pursue is

52 altruism. 


\section{Introduction}

Altruistic behaviors are non-reciprocal acts aimed at improving others' welfare, and

56 range from everyday behaviors like giving directions or donating to charity to costly,

57 extraordinary acts like heroic rescues and living organ donations. Reliable individual- and

58 situational-level predictors of altruism have been identified and position individual variation in

59 altruism within well-known frameworks of socio-affective motivation and behavior-including

60 sensitivity to others' distress and salience of need (Marsh et al., 2014; Slovic et al., 2017). But

61 less is known about what may be the most consequential source of variation in altruism: its non-

62 uniform geographic distribution. For example, impressive cross-national variation in altruism

63 emerges in the Charities Aid Foundation's (CAF) annual World Giving Index. This assessment

64 of global volunteering, charitable giving, and everyday helping has been compiled annually since

652010 and finds altruism to be up to four times more prevalent in the most- versus least-charitable

66 nations. These findings suggest that stable social and cultural variables likely contribute to

67 variation in multiple forms of altruism, a possibility also supported by previous investigations of

68 smaller geographic regions (Bach et al., 2017; Brethel-Haurwitz \& Marsh, 2014).

69 The variable most consistently associated with altruism at both the individual and

70 geographical level is subjective well-being (SWB; Aknin et al., 2012, 2019; Curry et al., 2018;

71 Dunn et al., 2008). Increases in objective indices of well-being (e.g., economic resources, health,

72 education) promote positive subjective states, which in turn promote engagement in intrinsically

73 meaningful behaviors (Jayawickreme et al., 2012) including those that improve the well-being of

74 others. Decades of experimental research draw conclusive bidirectional links between a variety

75 of altruistic behaviors and SWB. Increases in charitable giving, everyday helping, and donating

76 blood reliably lead to increased SWB (Aknin et al., 2012, 2018; Dunn et al., 2008; Jebb et al., 
77 2020; Layous et al., 2017). And increased SWB in turn leads to increases in various forms of

78 altruism at both individual and geographic levels. For example, individuals who report higher

79 well-being invest more hours in volunteer service (Thoits \& Hewitt, 2001), spend more money

80 on others (Aknin et al., 2012), and exert greater effort for others (Layous et al., 2017). Recent

81 work within in the United States has also linked geographical variation in SWB to increases in

82 altruistic kidney donation (Brethel-Haurwitz \& Marsh, 2014). What this work cumulatively

83 suggests - but no systematic effort has yet demonstrated - is that altruistic behaviors reflect

84 manifestations of a latent construct, the geographic prevalence of which can be reliably predicted

85 from global-scale variation in SWB.

The relationship between SWB and altruism is likely shaped by a variety of factors,

87 including cultural values (Diener et al., 1995; Diener \& Tay, 2015; Smith et al., 2013). For

88 example, individualist cultural values reliably predict increased national-level SWB (Diener et

89 al., 1995; Steel et al., 2018). In individualist cultures, the individual is viewed as the fundamental

90 unit of society, and autonomy and personal choice are valued relatively more than the needs and

91 concerns of the group (Hofstede et al., 2010; Triandis, 1995). Individualism thus promotes the

92 pursuit of personally valued goals and self-expression, such as selecting a profession or romantic

93 partner in accordance with one's values rather than to promote community harmony. These

94 emergent properties are putatively why individualism is consistently related to SWB, as variables

95 enhance SWB when they improve the ability to pursue and achieve meaningful goals (Diener et

96 al., 1995). To the extent that altruism may represent a personally meaningful outcome promoted

97 by SWB, individualism may also be positively associated with geographic variation in altruism.

98 Moreover, given differences in interpretations and manifestations of SWB across cultures that 
99 vary in individualism-collectivism (Steel et al., 2018), individualism may also moderate the 100 relationship between SWB and altruism.

To investigate these questions, we identified and compiled publicly available data about

102 seven forms of subjectively and objectively measured altruism drawn from five distinct sources

103 and which ranged from extraordinary (living organ donation) to everyday (helping a stranger)

104 behaviors. We then assessed associations between global-scale geographical variation in altruism 105 and SWB, as well as relevant demographic and cultural factors. We predicted SWB would be

106 positively associated with geographical variation in altruism, even controlling for key

107 sociodemographic covariates, cultural values, and shared history. We also predicted that, as

108 observed within the United States (Brethel-Haurwitz \& Marsh, 2014), increased SWB would

109 mediate the relationships between indices of objective well-being (e.g., wealth and health) and

110 geographic variation in altruism. Finally, we investigated how cultural values, such as

111 individualism, shape these effects.

Method

\section{Data collection and selection}

114 We conducted a search for datasets relevant to altruistic behavior at the national level

115 (e.g., data from the entire population of multiple countries, or from representative samples of the

116 populations of those countries). We ultimately identified and obtained large cross-national

117 datasets indexing seven forms of altruism. These included charitable donations, volunteering,

118 and everyday helping as indexed by responses to three questions from the Charities Aid

119 Foundation (Supplemental Table S2): Have you done any of the following in the past month:

120 Donated money to a charity? Volunteered your time to an organization? Helped a stranger, or

121 someone you didn't know who needed help? Using these data, we calculated countries' $(\mathrm{N}=153)$ 
122 2012-2016 mean score for each item to maximize measurement stability. We also compiled data

123 for total annual blood donations per capita $(2011-2013, \mathrm{~N}=136)$ from the World Health

124 Organization (Supplemental Table S2), total annual living kidney donations per million of

125 population $(2016, \mathrm{~N}=68)$ from the Donation \& Transplantation Institute (Supplemental Table

126 S2), total bone marrow donor registry members per capita (2018, N=54) from the World Marrow

127 Donor Association (Supplemental Table S2), and national-level assessments of the humane

128 treatment of non-human animals $(2014, \mathrm{~N}=48)$ from the World Animal Protection organization

129 (Supplemental Table S2). Per capita blood and marrow donation rates were calculated using total

130 population over 15 years of age from the World Factbook data compiled by the Central

131 Intelligence Agency (Supplemental Table S2). All measures were standardized to exhibit a mean

132 of 0 and a standard deviation of 1 . Following exploratory factor analyses and analyses of

133 reliability confirming convergence among these items, available scores for each nation (Median

134 items=5) were averaged to create composite altruism scores.

135 Drawing from prior explorations (Bach et al., 2017; Brethel-Haurwitz \& Marsh, 2014),

136 we considered potential national-level covariates linked to altruism, including: wealth (log-

137 transformed economic growth per capita; log GDP) and inequality (GINI coefficient), and

138 percent adult literacy from the World Bank, average lifespan, median age, sex ratio, and

139 population size from the World Factbook data compiled by the Central Intelligence Agency, and

140 cultural diversity as indexed by Fearon (Supplemental Table S2). In bivariate correlation

141 analyses, our composite altruism score was positively associated with five of these

142 sociodemographic variables. These included proportion of males (sex ratio) and four variables

143 that index features of objective well-being, including wealth (log GDP), health (average lifespan, 144 median age), and education (literacy) ( $\rho=.181-.477, P s<.05-.00001)$. Of these variables, $\log$ 
145 GDP, average lifespan, median age, and literacy were all highly intercorrelated $(\rho=.68-.86$, $146 \quad p<.0001)($ Table S1).

SWB comprises two distinct components: reflective judgements of life satisfaction, or

148 subjective thriving, and reports about the emotional quality of everyday experience in terms of

149 positive and negative emotions (Diener et al., 1995). Assessing both components is essential, as

150 they have distinct correlates (e.g., income and education are more closely related to thriving, but

151 chronic illness, loneliness, and smoking are more closely associated with daily emotional

152 experiences; see Kahneman \& Deaton, 2010). We compiled data collected by the Gallup World

153 polling organization regarding both of these components of SWB (Supplemental Table S2):

154 subjective thriving $(\mathrm{N}=134)$ and daily experience $(\mathrm{N}=135)$. Subjective thriving was measured via

155 ratings of respondents' present and future lives (for the next five years) on a "ladder" scale with

156 steps numbered from 0 to 10 ("0" indicating the worst possible life and "10" the best possible

157 life; note this scale is distinct from the ladder scale used to measure social status). Daily

158 experience was scored based on average responses (0-10) about daily emotional experience (e.g.,

159 feeling well-rested, being treated with respect, smiling/laughter, learning/interest, enjoyment,

160 physical pain, worry, sadness, stress, anger) with higher scores representing better days. See

161 Supplemental Table S2 for specific instructions and question wording.

162 Finally, we compiled data relevant to six cultural variables originally proposed and

163 measured by Hofstede and colleagues (Supplemental Table S2): power distance $(\mathrm{N}=102)$,

164 individualism $(\mathrm{N}=102)$, masculinity $(\mathrm{N}=102)$, uncertainty avoidance $(\mathrm{N}=102)$, long-term

165 orientation $(\mathrm{N}=86)$, and indulgence $(\mathrm{N}=81)$. Missing values were not imputed due to the high

166 percentage and non-random nature of these values. We also gathered data using the Ethnologue

167 language family index to use as a proxy for shared cultural history (Supplemental Tables S2). 
168

169

170

171

172

173

174

175 effects of objective well-being (log GDP, average lifespan, median age, literacy), sex ratio, the

176 effect life satisfaction, and the effect of daily experience. We then tested the bivariate

177 relationships between thriving and all seven forms of altruism using both Pearson and Spearman

178 correlations.

Mediation analyses included observations across 130 countries to assess the indirect effects of objective measures of well-being on altruism through SWB (Model 2). We calculated the magnitude and significance of the indirect effect using the product of coefficients method with 5000 bootstrap resamples to estimate bias-corrected $95 \%$ confidence intervals.

To test the effect of SWB on altruism while accounting for cultural variables, we conducted a series of multiple regression analyses with 5000 bootstrap resamples to estimate bias-corrected standard errors and 95\% confidence intervals. Our first model (Model 3a) incorporated observations from 75 countries with six cultural values as predictors controlling for $\log$ GDP, median age, average lifespan, sex ratio, and literacy. To account for covariation due to non-independent cultural histories across countries (Galton's problem), we identified language families with $>7$ countries in our dataset, yielding 4 language family groups among 57 countries

190 (Semitic, Italic, Germanic, Balto-Slavic) and grouped all others among the remaining 18 
191 countries. Language families were dummy coded and entered into the regression model to test

192 mean differences in altruism between Semitic $(\mathrm{N}=8)$, Italic $(\mathrm{N}=17)$, Balto-Slavic $(\mathrm{N}=11)$, and all

193 other families $(\mathrm{N}=18)$ relative to Germanic $(\mathrm{N}=21)$. We ran a regression model (Model $3 b)$ to

194 test whether the effect of individualism on altruism persisted after controlling for shared cultural

195 history, log GDP, average lifespan, median age, sex ratio, and literacy. We next entered SWB

196 (thriving) into our next regression model (Model 4a) accounting for six cultural values, log GDP,

197 average lifespan, median age, literacy, and sex ratio across 75 countries, and then tested the

198 interaction effect of SWB and individualism on altruism (Model 4b). We then examined this

199 interaction effect in a larger sub-sample of 90 countries with available individualism and SWB

200 data (Model 4c).

201 In our final set of tests, we first conducted another mediation analysis to confirm the

202 indirect effects in a subsample of 90 countries with available individualism data (Model 5).

203 Finally, we conducted a moderated mediation analysis to test whether the indirect effect of

204 wealth on altruism through SWB would vary across levels of individualism (Model 6). Among

20590 countries, we again estimated the magnitude and significance of the indirect effects at

206 different levels of individualism using the product of coefficients method with 5000 bootstrap

207 resamples to estimate bias-corrected $95 \%$ confidence intervals.

\section{Results}

209 Distinct outcomes or indices of a latent construct?

210 An exploratory factor analysis using a principal-axis factor extraction across the seven

211 subjectively and objectively measured forms of altruistic behavior (charitable donations,

212 volunteering, everyday helping, blood donations, living kidney donations, bone marrow donor

213 registrations, and humane treatment of non-human animals) yielded a two-factor solution, 
214 however, all variables loaded more strongly on the first factor, which explained $38 \%$ of all

215 variance; all but one variable (marrow donation) yielded loadings $>0.5$ on this factor (range:

216 0.42-0.79). Scores across the seven indicators yielded a Cronbach's $\alpha=.785$, with an ICC=.787,

$217 \mathrm{CI}_{95}[0.63,0.89], F(25,250)=4.68, P<.001$. Together, these outcomes support the conclusion that

218 the seven forms of altruism are manifestations of a common latent construct. Mean scores using

219 all available items for each country were therefore calculated (Median items=5). Composite

220 scores were approximately normally distributed $(Z=-1.27-1.52$, skewness $=0.481$, s.e.m. $=.197$;

221 kurtosis=-.537, s.e.m.=.391).

\section{The global relationship between SWB and altruism}

Following prior findings, we hypothesized that country-level indicators of objective well-

224 being, particularly per-capita wealth, would be associated with country-level altruism, but SWB

225 would explain geographic variance in altruism even when controlling for relevant

226 sociodemographic variables (Brethel-Haurwitz \& Marsh, 2014). Our first stepwise model (Model

227 1a; $\mathrm{N}=130$ ) was a multiple linear regression incorporating wealth, median age, average lifespan,

228 sex ratio, and literacy. In the first step assessing the relationship between indicators of objective

229 well-being and altruism, $\chi^{2}(5)=50.35, P<.0001$, we found unique variance associated only with

230 wealth persisted as a predictor of altruism $\left(b=.41, S E=.09, C I_{95 \%}=[.24 .59], P<.001\right)$. In stepwise

231 analyses, we next included the two indices of SWB: current and anticipated life satisfaction

232 (subjective thriving) and daily life experiences. Inclusion of thriving into the model (Model 1b;

$233 \mathrm{~N}=130)$ significantly increased total variance explained, $R^{2}$ change $=.13, \chi^{2}(6)=94.07, P<.0001$. The

234 association between SWB (subjective thriving) and altruism was robust $(b=1.65, S E=.28$,

$\left.235 C I_{95 \%}=[1.132 .23], P<.0001\right)$, whereas the association between wealth and altruism decreased but

236 remained statistically significant $\left(b=.25, S E=.08, C I_{95 \%}=[.09 .41], P=.002\right)$. Inclusion of our 
237 second measure of well-being indexing daily life experiences did not increase variance explained

238 by the model (Model $1 \mathrm{c} ; \mathrm{N}=130$ ), $R_{\text {change }}^{2}=.0005$, and this measure was not related to altruism,

$239 P=.79$, (Table 1). (Note that both linear and quadratic trends were also observed in the

240 associations between wealth and both SWB and altruism. In both cases, the linear relationships

241 were attenuated in wealthier countries; Supplementary Table S3; Figure S1ab).

242 Further supporting the robustness of the link between SWB and altruism, we considered

243 the relationship between thriving and each of the seven individual indices of altruism separately.

244 We assessed both bivariate parametric and non-parametric associations as well as the residual

245 relationship after controlling for our five covariates (log GDP, average lifespan, median age,

246 literacy, and sex ratio). Across the seven indices, we found associations between SWB and

247 altruism to be generally robust and consistent (Figure 1). This is noteworthy given that these

248 indices of altruism reflect both personal and institutional forms of giving, which prior findings

249 suggest may be distinct subtypes of altruistic behavior (Enelamah \& Thanh, 2019).

250 We next conducted a mediation analysis to assess the indirect effect of wealth on altruism

251 through thriving at a global scale (Model 2; N=130). Our model revealed significant partial

252 indirect effect of wealth (log GDP) on altruism through thriving (indirect effect $=.16, S E=.05$,

$\left.253 C I_{95 \%}=[.08 .29], P=.001\right)$ as well as an indirect effect of health (average lifespan) on altruism

254 through thriving (indirect effect=.01, $\left.S E=.01, C I_{95}=[.01 .03], P=.009\right)$. Both wealth $(b=.10$,

$\left.255 S E=.02, C I_{95 \%}=[.06 .15], P<.0001\right)$ and health $\left(b=.01, S E=.003, C I_{95 \%}=[.003 .02], P=.004\right)$ were

256 significant predictors of thriving, and thriving $\left(b=1.65, S E=.28, C I_{95} \%=[1.132 .23], P<.0001\right)$ was

257 highly predictive of altruism (Table 2). This result suggests first that the previously reported

258 effect of SWB on altruism in the United States persists at an international scale, and expands this

259 framework by indicating effects of two indices of objective well-being (wealth and health). 
260 Third, it suggests that geographic variation in SWB statistically predicts not only extraordinary

261 forms of altruism (non-directed living kidney donation), but multiple forms of altruistic behavior

262 including all living kidney donations, blood and marrow donations, and the humane treatment of

263 animals.

264 Cultural values that promote the relationship between SWB and altruism

265 Following robust evidence of the influence of cultural values on both SWB and altruism

266 (Diener et al., 1995), we next considered relationships among SWB, altruism, and cultural

267 values. Among countries with available data on cultural values, shared cultural history, and

268 thriving, we evaluated whether the relationship between SWB and altruism would change after

269 accounting for six overarching cultural values, shared cultural history, wealth, and key

270 sociodemographic covariates in a series of regression analyses. In our first regression (Model 3a;

$271 \mathrm{~N}=75$ ), we assessed the relationship between cultural values and altruism controlling for

272 objective indices of well-being, $\chi^{2}(11)=172.62, P<.0001$. We found that individualism $(b=.009$,

$\left.273 S E=.003, C I_{95 \%}=[.003 .02], P=.008\right)$ and indulgence $\left(b=.008, S E=.003, C I_{95 \%}=[.002 .01], P=.007\right)$

274 were the only cultural values linked to altruism. (Given some inconsistencies in how

275 individualism is conceptualized and measured, we also sought to confirm the individualism-

276 altruism association using an independent 10-point individualism index (Diener et al., 1995) in

277 countries with available data and found that this relationship persisted; Supplemental Table S3).

278 Although these results offer evidence for a meaningful relationship between cultural values and

279 altruism, this covariation may alternatively be explained by geographical autocorrelation due to

280 the non-independent cultural histories shared across countries (Galton's problem). Following

281 previous approaches, we used language family as a proxy for shared cultural history and entered

282 this variable in our second regression (Model 3b; $\mathrm{N}=75), \chi^{2}(15)=182.06, P<.0001, R_{\text {change }}^{2} .06$. 
283 We found significant differences in altruism among language families (dummy coded), $P s<.05$.

284 Importantly, we identified a persistent relationship between individualism and altruism $(b=.007$,

$\left.285 S E=.004, C I_{95 \%}=[.0002 .02], P=.05\right)$ controlling for key country-level covariates, cultural values,

286 and language family (Table 3). Notably, language family accounted for the variance in altruism

287 explained by indulgence. relationship between SWB and altruism (Model 4a; N=75), $\chi^{2}(12)=166.98, P<.0001$. Among

290 countries with available data, we again found a robust relationship between individualism and

291 altruism $\left(b=.009, S E=.004, C I_{95 \%}=[.002 .02], P=.017\right)$. However, our previously established

292 significant relationship between $\mathrm{SWB}$ and altruism became non-significant $(b=.18, S E=.41$,

$\left.293 C I_{95 \%}=[-.531 .13], P=.66\right)$. Given this outcome, we considered whether the relationship between

294 SWB and altruism may be moderated by individualism. Controlling for key covariates, our

295 model testing moderation (Model 4b; $=75), \chi^{2}(13)=237.29, P<.0001, R_{\text {change }}=.04$, revealed a

296 significant interaction between SWB and individualism $(b=.038, S E=.013, C I 95 \%=[.01 .06]$,

$297 P=.003$ ), such that the positive relationship between SWB and altruism increased as

298 individualistic values increased. Because data in this sub-sample were missing for several

299 cultural variables, including language families, we confirmed this interaction effect in a larger

300 sub-sample of countries (Model 4c; $N=90), \chi^{2}(8)=156.22, P<.0001$ (Table 4; Figure 2).

301 The observed interaction between SWB and individualism suggests that individualism

302 may moderate the main effect of SWB on altruism as well as the mediating effect of national

303 wealth on altruism through SWB. Thus, before proceeding, we examined whether the indirect

304 effect of wealth on altruism through SWB persisted after listwise excluding 40 countries with

305 missing cultural data (Model 5; N=90). This mediation model revealed similar results, with an 
306 indirect of wealth ( $\log$ GDP) on altruism through SWB (indirect effect $=.15, S E=.08, C I_{95}=[.02$

$307.33], P=.05$ ) as well as an indirect effect of health (average lifespan) on altruism through SWB

308 (indirect effect $\left.=.02, S E=.008, C I_{95 \%}=[.005 .04], P=.03\right)$. Wealth $\left(b=0.09, S E=.05, C I_{95 \%}=[.01\right.$

$309.19], P=.04)$ and health $\left(b=0.01, S E=.005, C I_{95 \%}=[.003 .02], P=.02\right)$ both remained significant

310 predictors of thriving, and thriving remained a highly significant predictor of altruism $(b=1.61$,

$311 S E=.30, C_{95 \%}=[1.07$ 2.23], $P<0.001)$ (Table 5). We thus tested whether the indirect effects of

312 both wealth and health on altruism through SWB were moderated by national-levels of

313 individualism (Model 6; N=90). This moderated mediation analysis found that these indirect

314 effects were not present in countries with individualism scores below the global mean, but

315 increased among countries at and above mean individualism (Tables 6-7).

316 We plot Z-scored geographical variations in altruism, SWB (thriving), individualism,

317 average lifespan, and per capita GDP in Figure 3.

\section{Discussion}

We find the first evidence for strong geographic convergence among seven diverse forms

320 of altruism - from everyday behaviors like volunteering to rarer forms of extraordinary altruism

321 like living organ or marrow donation-supporting the contention that these behaviors reflect a

322 common latent construct. Further, we find robust evidence for global-scale geographic

323 covariation between SWB (thriving and life satisfaction) and all of these forms of altruism,

324 consistent with evidence from the laboratory and smaller geographic regions (Aknin et al., 2019;

325 Bach et al., 2017; Brethel-Haurwitz \& Marsh, 2014; Helliwell et al., 2019). Although we found

326 geographic variation in altruism to be strongly and positively associated with objective indices of

327 well-being (wealth and health), altruism's association with SWB persisted even after accounting

328 for these. The indirect effect of wealth on altruism through SWB previously observed in the 
329 United States was also observed in this international sample, and was especially robust in

330 countries that highly value individualism. Together, these findings suggest that when resources

331 and cultural values provide the objective and subjective means for pursuing individual goals,

332 among the goals people become more inclined to pursue is altruism.

\section{The relationship between well-being and altruism}

334 The present work replicates prior findings that geographic variation in both objective 335 well-being and SWB positively predict altruistic behavior. It also extends previous research

336 showing robust associations between life satisfaction and at least two forms of altruism

337 (charitable giving and volunteering) (Aknin et al., 2019; Helliwell et al., 2019; Jenkinson et al.,

338 2013). Relatively rare, costly, and objectively measured forms of altruism (blood, marrow, and

339 organ donations), and even behaviors towards non-human animals, follow a similar pattern.

340 Well-being is a multidimensional construct that reflects both objectively measured

341 indicators of flourishing and subjective assessments like mood and quality of life (Kahneman et

342 al., 1999). Objective well-being typically reflects the satisfaction of basic human needs such as

343 economic resources, good health, and education (Oswald \& Wu, 2010). The relationship between

344 wealth and altruism is somewhat controversial, with some studies linking individual-level wealth

345 and social status to greater selfishness and reduced helpfulness (Piff et al., 2010). However, a

346 pre-registered study did not replicate these findings (Stamos et al., 2019), consistent with

347 findings from large, representative samples that higher status and wealth correspond to

348 volunteering and civic engagement (Gittell \& Tebaldi, 2006; Hughes \& Luksetich, 2008;

349 Korndörfer et al., 2015). We also provide evidence that national-level health (longevity) plays a

350 critical role within this framework, supporting associations among health, SWB, and altruism 
351 (Kumar et al., 2012; Post, 2005). Together, these findings offer reassurance that there may be no

352 inherent conflict between doing well and doing good.

353 SWB indicators go beyond measures of objective well-being in capturing quality of life

354 (Diener et al., 1995; Diener \& Seligman, 2018). We found national-level SWB (reported thriving

355 and life satisfaction) explained variation in altruism better than measures of daily affect,

356 consistent with evidence that evaluations of life satisfaction are more robustly associated with

357 objective well-being (e.g., income) than reports of daily emotion (Diener et al., 2010; Kahneman

358 \& Deaton, 2010). SWB generally follows exogenous, objective indices of well-being and in turn

359 leads to voluntary, beneficent behaviors that are pursued for their own sake and further promote

360 well-being (Jayawickreme et al., 2012). At the individual level, these include common altruistic

361 behaviors like volunteering and charitable giving (Aknin et al., 2012; Dunn et al., 2008;

362 Jayawickreme et al., 2012; Weinstein \& Ryan, 2010), which promote the well-being of both

363 altruists and beneficiaries (Curry et al., 2018; Weinstein \& Ryan, 2010). This suggests a

364 bidirectional relationship between SWB and altruism, comprising a positive feedback loop

365 whereby increases in well-being lead to altruistic behaviors that in turn promote increases in

366 well-being (Aknin et al., 2012, 2015). Although we did not directly test this mechanism, our

367 findings are consistent with the possibility of such positive feedback loops on a global scale.

368 Individualism and personally-driven altruism

369 In our models, individualism was positively associated with both SWB and altruism, and

370 moderated the relationship between them such that SWB was more strongly associated with

371 altruism in nations that value individualism. To the extent a robust positive geographic

372 relationship between individualism and altruism appears counterintuitive, it may reflect the

373 common conflation of individualism with selfishness. However, present results together with 
374 previous work (Steel et al., 2018) may resolve this apparent paradox, in that individualist cultural

375 values are reliably associated with SWB (Diener et al., 1995), which promotes altruism.

376 Individualist values also moderated the indirect effects between objective well-being and

377 altruism. This may be related to altruism — along with other behaviors — reflecting personal

378 choices instead of role and obligation in more individualist nations. Individualist values may

379 follow a cultural de-emphasis on kin-based institutions (Schulz et al., 2018) and greater exposure

380 to "globalized" attitudes (more parochial motivations abandoned in favor of cosmopolitan ones),

381 which may promote altruism particularly toward strangers (Buchan et al., 2009). By contrast,

382 collectivist cultures emphasize adherence to intensive kin-based institutional norms, which

383 reward greater conformity, obedience, and in-group loyalty. Rather than selfishness per se, then,

384 individualism may promote the pursuit of personally relevant goals that benefit the welfare of

385 others with relatively less regard to social ties. Although this is reassuring, given rising

386 individualist values globally (Santos et al., 2017), future research should consider potential costs

387 of individualistic forms of altruism, which may not promote the formation or strengthening of

388 specific relationships to the degree that more relationally-driven altruism does.

389 Limitations

390 Limitations of our findings include their necessarily correlational and cross-sectional

391 nature. Longitudinal data on multiple forms of altruism were either unavailable or available only

392 across time spans too short for meaningful cross-lagged analyses. In addition, complete data on

393 cultural and altruistic indicators were not available for all nations. We chose to forgo imputation

394 methods due to the non-random nature of missing data in our sample. Thus, it should be noted

395 that our data only represent a subset of the world's 195 countries. While our primary analyses

396 arguably involve an impressive fraction of the world's population, analyses that include cultural 
397 data include fewer countries because we were limited by available data. Sample sizes like these

398 can be influenced by outliers. However, we made several efforts to account for potential bias and

399 outliers among included cases, including statistical approaches robust to bias (bootstrap

400 resampling) and non-parametric analyses that are robust to outliers (Spearman rank correlations),

401 which yielded results very similar to our parametric analyses.

402 Notably, national-level wealth exhibited a quadratic relationship with both SWB and

403 altruism (Supplementary Table S3; Figure S1ab). These nonlinear relationships are important

404 considerations in the contexts of our findings: neither SWB nor altruism continue rising linearly

405 as nations approach extreme levels of wealth. Mechanisms underlying this nonlinear relationship

406 should be explored in future work.

\section{Conclusion}

Increasingly, national and international organizations that promote economic

409 development are expanding their priorities to include measures of both objective and subjective 410 well-being (United Nations, 2015). Although SWB often follows increases in objective indices

411 of well-being (e.g., wealth, health), these constructs are distinct in important ways. Our findings

412 reinforce the importance of focusing specifically on SWB, which robustly and consistently

413 predicts multiple forms of altruism across nations. Thus, not only does geographic variation in

414 altruism reflect a coherent construct that varies across nations, but altruism is positively

415 associated with both material and subjective thriving, as well as cultural values linked to

416 thriving. This suggests not only that altruistic goals are intrinsically and globally valued, but that

417 they can be promoted by factors that foster flourishing, including improved health, wealth, and

418 education. 


\section{References}

421

422

423

424

425

426

427

428

429

430

431

432

433

434

435

436

437

438

439

440

441

442

Aknin, L. B., Broesch, T., Kiley Hamlin, J., \& Van De Vondervoort, J. W. (2015). Prosocial behavior leads to happiness in a small-scale rural society. Journal of Experimental Psychology: General, 144(4), 788-795. https://doi.org/10.1037/xge0000082

Aknin, L. B., Dunn, E. W., \& Norton, M. I. (2012). Happiness Runs in a Circular Motion: Evidence for a Positive Feedback Loop between Prosocial Spending and Happiness. Journal of Happiness Studies, 13(2), 347-355. https://doi.org/10.1007/s10902-011-9267-5

Aknin, L. B., Van de Vondervoort, J. W., \& Hamlin, J. K. (2018). Positive feelings reward and promote prosocial behavior. Current Opinion in Psychology, 20, 55-59. https://doi.org/10.1016/j.copsyc.2017.08.017

Aknin, L. B., Whillians, A. V., Norton, M. I., \& Dunn, E. W. (2019). Happiness and prosocial behavior: An evaluation of the evidence. In World Happiness Report 2019 (pp. 67-85).

Bach, R. A., Defever, A. M., Chopik, W. J., \& Konrath, S. H. (2017). Geographic variation in empathy: A state-level analysis. Journal of Research in Personality, 68, 124-130. https://doi.org/10.1016/j.jrp.2016.12.007

Brethel-Haurwitz, K. M., \& Marsh, A. A. (2014). Geographical Differences in Subjective WellBeing Predict Extraordinary Altruism. Psychological Science, 25(3), 762-771. https://doi.org/10.1177/0956797613516148

Buchan, N. R., Grimalda, G., Wilson, R., Brewer, M., Fatas, E., \& Foddy, M. (2009). Globalization and human cooperation. Proceedings of the National Academy of Sciences, 106(11), 4138-4142.

Curry, O. S., Rowland, L. A., Van Lissa, C. J., Zlotowitz, S., McAlaney, J., \& Whitehouse, H. (2018). Happy to help? A systematic review and meta-analysis of the effects of performing 
443

444

445

446

447

448

449

450

451

452

453

454

455

456

457

458

459

460

461

462

463

464

465

acts of kindness on the well-being of the actor. Journal of Experimental Social Psychology, 76, 320-329. https://doi.org/10.1016/j.jesp.2018.02.014

Diener, E., Diener, M., \& Diener, C. (1995). Factors Predicting the Subjective Well-Being of Nations. Journal of Personality and Social Psychology, 69(5), 851-864. https://doi.org/10.1037/0022-3514.69.5.851

Diener, E., Harter, J., \& Arora, R. (2010). Wealth and Happiness Across the World: Material Prosperity Predicts Life Evaluation, Whereas Psychosocial Prosperity Predicts Positive Feeling. Journal of Personality and Social Psychology, 99(1), 52-61. https://doi.org/10.1037/a0018066

Diener, E., \& Seligman, M. E. P. (2018). Beyond Money: Progress on an Economy of WellBeing. Perspectives on Psychological Science, 13(2), 171-175. https://doi.org/10.1177/1745691616689467

Diener, E., \& Tay, L. (2015). Subjective well-being and human welfare around the world as reflected in the Gallup World Poll. International Journal of Psychology, 50(2), 135-149. https://doi.org/10.1002/ijop.12136

Dunn, E. W., Aknin, L. B., \& Norton, M. I. (2008). Spending money on others promotes happiness. Science, 319(5870), 1687-1688. https://doi.org/10.1126/science.1150952

Enelamah, N., \& Thanh, T. (2019). Dimensions of altruism behaviors among Americans in the General Social Survey. Journal of Human Behavior in the Social Environment, 30(2), 213227. https://doi.org/10.1080/10911359.2019.1673274

Gittell, R., \& Tebaldi, E. (2006). Charitable giving: Factors influencing giving in U.S. states. Nonprofit and Voluntary Sector Quarterly, 35(4), 721-736. https://doi.org/10.1177/0899764006289768 
Helliwell, J. F., Huang, H., \& Wang, S. (2019). Changing world happiness. In World Happiness Report 2019 (pp. 11-45).

Hofstede, G., Hofstede, G. J., \& Minkov, M. (2010). Cultures and Organizations. McGraw. https://doi.org/10.1007/s11569-007-0005-8

Hughes, P., \& Luksetich, W. (2008). Income volatility and wealth: The effect on charitable giving. Nonprofit and Voluntary Sector Quarterly, 37(2), 264-280. https://doi.org/10.1177/0899764007310416

Jayawickreme, E., Forgeard, M. J. C., \& Seligman, M. E. P. (2012). The engine of well-being. Review of General Psychology, 16(4), 327-342. https://doi.org/10.1037/a0027990

Jebb, A. T., Morrison, M., Tay, L., \& Diener, E. (2020). Subjective Well-Being Around the World: Trends and Predictors Across the Life Span. Psychological Science, 31(3), 293-305. https://doi.org/10.1177/0956797619898826

Jenkinson, C. E., Dickens, A. P., Jones, K., Thompson-coon, J., Taylor, R. S., Rogers, M., Bambra, C. L., Lang, I., \& Richards, S. H. (2013). Is volunteering a public health intervention? A systematic review and meta-analysis of the health and survival of volunteers. BMC Public Health, 13(1), 1-10.

Kahneman, D., \& Deaton, A. (2010). High income improves evaluation of life but not emotional well-being. Proceedings of the National Academy of Sciences, 107(38), 16489-16493. https://doi.org/10.1073/pnas.1011492107

Kahneman, D., Diener, E., \& Schwarz, N. (1999). Well-being: The foundations of hedonic psychology. In Russell Sage Foundation. https://doi.org/10.7758/9781610443258

Korndörfer, M., Egloff, B., \& Schmukle, S. C. (2015). A large scale test of the effect of social class on prosocial behavior. PLoS ONE, 10(7), 1-48. 
https://doi.org/10.1371/journal.pone.0133193

490

491

492

493

494

495

Kumar, S., Calvo, R., Avendano, M., Sivaramakrishnan, K., \& Berkman, L. F. (2012). Social support, volunteering and health around the world: Cross-national evidence from 139 countries. Social Science \& Medicine, 74(5), 696-706. https://doi.org/10.1016/j.socscimed.2011.11.017

Layous, K., Nelson, S. K., Kurtz, J. L., \& Lyubomirsky, S. (2017). What triggers prosocial effort? A positive feedback loop between positive activities, kindness, and well-being. Journal of Positive Psychology, 12(4), 385-398. https://doi.org/10.1080/17439760.2016.1198924

Marsh, A. A., Stoycos, S. A., Brethel-Haurwitz, K. M., Robinson, P., VanMeter, J. W., \& Cardinale, E. M. (2014). Neural and cognitive characteristics of extraordinary altruists. Proceedings of the National Academy of Sciences, 111(42), 15036-15041. https://doi.org/10.1073/pnas.1408440111

Oswald, A. J., \& Wu, S. (2010). Objective confirmation of subjective measures of human wellbeing: Evidence from the U.S.A. Science, 327(5965), 576-579. https://doi.org/10.1126/science.1180606

Piff, P. K., Kraus, M. W., Côté, S., Cheng, B. H., \& Keltner, D. (2010). Having Less, Giving More: The Influence of Social Class on Prosocial Behavior. Journal of Personality and Social Psychology, 99(5), 771-784. https://doi.org/10.1037/a0020092

Post, S. G. (2005). Altruism, Happiness, and Health : It's Good to Be Good. International Journal of Behavioral Medicine, 12(2), 66-77.

Santos, H. C., Varnum, M. E. W., \& Grossmann, I. (2017). Global Increases in Individualism. Psychological Science, 28(9), 1228-1239. https://doi.org/10.1177/0956797617700622 
512 Schulz, J. F., Bahrami-Rad, D., Beauchamp, J. P., \& Henrich, J. (2018). The Church, intensive

513 kinship, and global psychological variation. Science, 366(6466), 1-12.

514 https://doi.org/10.1126/science.aau5141

515 Slovic, P., Västfjäll, D., Erlandsson, A., \& Gregory, R. (2017). Iconic photographs and the ebb

516 and flow of empathic response to humanitarian disasters. Proceedings of the National

517 Academy of Sciences, 114(4), 640-644. https://doi.org/10.1073/pnas.1613977114

518 Smith, S. W. S. L., Lapinski, M. K. M. J., Bresnahan, M. J., Smith, S. W. S. L., Smith, M. K.,

519 Lapinski, M. K. M. J., \& Bresnahan, S. L. (2013). Conceptual Aspects of Altruism in Cross-

520 Cultural Contexts. In V. D. (Ed.), Altruism in Cross-Cultural Perspective (pp. 17-29).

Stamos, A., Lange, F., Huang, S., \& Dewitte, S. (2019). Having Less, Giving More? Two Preregistered Replications of the Relationship Between Social Class and Prosocial Behavior. Journal of Research in Personality, 84(103902), 1-9.

Steel, P., Taras, V., Uggerslev, K., \& Bosco, F. (2018). The Happy Culture: A Theoretical, MetaAnalytic, and Empirical Review of the Relationship Between Culture and Wealth and https://doi.org/10.1016/J.JRP.2019.103902

Thoits, P. A., \& Hewitt, L. N. (2001). Volunteer Work and Well-Being. Journal of Health and Social Behavior, 42(2), 115-131.

532 Triandis, H. C. (1995). Individualism and Collectivism. Routledge. https://doi.org/10.4324/9780429499845

534 United Nations. (2015). Transforming our world: the 2030 agenda for sustainable development. 
535 https://www.un.org/ga/search/view_doc.asp?symbol=A/RES/70/1\&Lang=E

536 Weinstein, N., \& Ryan, R. M. (2010). When Helping Helps: Autonomous Motivation for

537 Prosocial Behavior and Its Influence on Well-Being for the Helper and Recipient. Journal

538 of Personality and Social Psychology, 98(2), 222-244. https://doi.org/10.1037/a0016984

539 
Table 1. Regression table for model 1, assessing the relationships between SWB and altruism controlling for sociodemographic variables.

\begin{tabular}{|c|c|c|c|c|c|c|}
\hline \multirow[b]{2}{*}{ Altruism } & \multicolumn{2}{|c|}{$\begin{array}{l}\text { Model 1a } \\
\mathrm{N}=130 \\
\mathrm{R}^{2}=.315 \\
\end{array}$} & \multicolumn{2}{|c|}{$\begin{array}{l}\text { Model 1b } \\
\mathrm{N}=130 \\
\mathrm{R}^{2}=.444\end{array}$} & \multicolumn{2}{|c|}{$\begin{array}{l}\text { Model 1c } \\
\mathrm{N}=130 \\
\mathrm{R}^{2}=.445\end{array}$} \\
\hline & $b(S E)$ & $\begin{array}{c}\text { bias-corrected } \\
95 \% \mathrm{CI} \\
\end{array}$ & $b(S E)$ & $\begin{array}{c}\text { bias-corrected } \\
95 \% \mathrm{CI} \\
\end{array}$ & $b(S E)$ & $\begin{array}{c}\text { bias-corrected } \\
95 \% \mathrm{CI} \\
\end{array}$ \\
\hline Subjective thriving & & & $1.652(.277)^{* * *}$ & {$[1.13,2.23]$} & $1.6(.345)^{* * *}$ & {$[.94,2.29]$} \\
\hline Daily experience & & & & & $.025(.093)$ & {$[-.16, .21]$} \\
\hline Log GDP per capita & $.411(.088)^{* * *}$ & {$[.24, .59]$} & $.248(.08)^{* *}$ & {$[.09, .41]$} & $.247(.082)^{* *}$ & {$[.09, .41]$} \\
\hline Average lifespan & $.0003(.013)$ & {$[-.02, .03]$} & $-.014(.011)$ & {$[-.04, .01]$} & $-.014(.011)$ & {$[-.03, .01]$} \\
\hline Median age & $-.022(.012)$ & {$[-.05, .001]$} & $-.012(.011)$ & {$[-.03, .01]$} & $-.012(.011)$ & {$[-.03, .01]$} \\
\hline Literacy & $-.048(.365)$ & {$[-.84, .60]$} & $.01(.348)$ & {$[-.75, .65]$} & $.011(.351)$ & {$[-.77, .64]$} \\
\hline Sex ratio (M:F) & $.475(1.117)$ & {$[-.06,3.73]$} & $.398(.959)$ & {$[-.09,3.08]$} & $.404(1.012)$ & {$[-.09,3.15]$} \\
\hline
\end{tabular}


Table 2. Regression table for model 2 assessing the indirect effect of objective measures of wellbeing on altruism through SWB.

\begin{tabular}{|c|c|c|c|c|}
\hline \multirow[b]{2}{*}{ Subjective Thriving } & \multicolumn{4}{|c|}{$\begin{array}{c}\text { Model } 2 \\
\mathrm{~N}=130\end{array}$} \\
\hline & $b(S E)$ & $\begin{array}{c}\text { bias-corrected } \\
95 \% \text { CI }\end{array}$ & & \\
\hline Log GDP per capita & $.099(.024)^{* * *}$ & {$[.06, .15]$} & & \\
\hline Average lifespan & $.009(.003)^{* *}$ & {$[.003, .02]$} & & \\
\hline Median age & $-.006(.003)$ & {$[-.01, .001]$} & & \\
\hline Literacy & $-.035(.087)$ & {$[-.22, .13]$} & & \\
\hline Sex ratio $(M: F)$ & $.047(.196)$ & {$[-.24, .57]$} & & \\
\hline Altruism & $b(S E)$ & $\begin{array}{c}\text { bias-corrected } \\
95 \% \text { CI } \\
\end{array}$ & $\begin{array}{c}\text { indirect effect } \\
(S E)\end{array}$ & $\begin{array}{c}\text { bias-corrected } \\
95 \% \mathrm{CI}\end{array}$ \\
\hline Subjective thriving & $1.652(.277)^{* * *}$ & {$[1.13,2.23]$} & & \\
\hline Log GDP per capita & $.248(.08)^{* *}$ & {$[.09, .41]$} & $.163(.051)^{* *}$ & {$[.08, .29]$} \\
\hline Average lifespan & $-.014(.011)$ & {$[-.04, .01]$} & $.014(.006)^{* *}$ & {$[.01, .03]$} \\
\hline Median age & $-.012(.011)$ & {$[-.03, .01]$} & $-.01(.006)$ & {$[-.02, .0004]$} \\
\hline Literacy & $.01(.348)$ & {$[-.75, .65]$} & $-.057(.146)$ & {$[-.40, .20]$} \\
\hline Sex ratio (M:F) & $.398(.959)$ & {$[-.09,3.08]$} & $.077(.312)$ & {$[-.39, .95]$} \\
\hline
\end{tabular}

Note. Standard errors (SE) and confidence intervals (CI) are bias-corrected using 5000 bootstrap resamples; ${ }^{* * *} \mathrm{p}<.001,{ }^{* *} \mathrm{p}<.01,{ }^{*} \mathrm{p}<.05$ 
Table 3. Regression table for model 3 assessing the relationships between SWB, culture, and altruism controlling for sociodemographic variables.

\begin{tabular}{|c|c|c|c|c|}
\hline \multirow[b]{2}{*}{ Altruism } & \multicolumn{2}{|c|}{$\begin{array}{c}\text { Model 3a } \\
N=75 \\
R^{2}=.656\end{array}$} & \multicolumn{2}{|c|}{$\begin{array}{c}\text { Model 3b } \\
\mathrm{N}=75 \\
\mathrm{R}^{2}=.715\end{array}$} \\
\hline & $b(S E)$ & $\begin{array}{l}\text { bias-corrected } \\
95 \% \mathrm{CI}\end{array}$ & $b(S E)$ & $\begin{array}{l}\text { bias-corrected } \\
95 \% \mathrm{CI}\end{array}$ \\
\hline \multicolumn{5}{|l|}{ Cultural values } \\
\hline Power distance & $-.004(.004)$ & {$[-.01, .003]$} & $.00004(.004)$ & {$[-.01, .01]$} \\
\hline Individualism & $.009(.003)^{* *}$ & {$[.003, .02]$} & $.007(.004)^{*}$ & {$[.0002, .02]$} \\
\hline Masculinity & $-.003(.002)$ & {$[-.01, .002]$} & $-.003(.002)$ & {$[-.01, .001]$} \\
\hline Uncertainty avoidance & $-.003(.003)$ & {$[-.01, .003]$} & $.001(.004)$ & {$[-.01, .01]$} \\
\hline Long-term orientation & $.002(.003)$ & {$[-.005, .01]$} & $-.001(.003)$ & {$[-.01, .01]$} \\
\hline Indulgence & $.008(.003)^{* *}$ & {$[.002, .01]$} & $.003(.003)$ & {$[-.003, .01]$} \\
\hline \multicolumn{5}{|l|}{ Language family } \\
\hline Semitic $>$ Germanic & & & $-.626(.271)^{*}$ & {$[-1.18,-.10]$} \\
\hline Italic $>$ Germanic & & & $-.518(.173)^{* *}$ & {$[-.87,-.19]$} \\
\hline $\begin{array}{l}\text { Balto-Slavic > } \\
\text { Germanic }\end{array}$ & & & $-.71(.233)^{* *}$ & {$[-1.13,-.20]$} \\
\hline Other $>$ Germanic & & & $-.435(.179)^{*}$ & {$[-.79,-.08]$} \\
\hline Log GDP per capita & $.172(.163)$ & {$[-.15, .50]$} & $.163(.181)$ & {$[-.18, .54]$} \\
\hline Average lifespan & $-.003(.016)$ & {$[-.03, .03]$} & $.001(.017)$ & {$[-.04, .03]$} \\
\hline Median age & $-.002(.018)$ & {$[-.04, .03]$} & $.004(.019)$ & {$[-.03, .05]$} \\
\hline Literacy & $-.097(.891)$ & {$[-1.9,1.62]$} & $.168(.989)$ & {$[-1.6,2.22]$} \\
\hline Sex ratio (M:F) & $3.294(1.768)$ & {$[.02,6.94]$} & 3.068 (1.744) & {$[-.18,6.85]$} \\
\hline
\end{tabular}

Note. Standard errors (SE) and confidence intervals (CI) are bias-corrected using 5000 bootstrap resamples; ${ }^{* * *} \mathrm{p}<.001,{ }^{* *} \mathrm{p}<.01,{ }^{*} \mathrm{p}<.05$ 
Table 4. Regression table for model 4 assessing the SWB $\mathrm{x}$ individualism interaction effect on altruism controlling for sociodemographic variables.

\begin{tabular}{|c|c|c|c|c|c|c|}
\hline \multirow[b]{2}{*}{ Altruism } & \multicolumn{2}{|c|}{$\begin{array}{l}\text { Model } 4 \mathrm{a} \\
\mathrm{N}=75 \\
\mathrm{R}^{2}=.656\end{array}$} & \multicolumn{2}{|c|}{$\begin{array}{l}\text { Model } 4 \mathrm{~b} \\
\mathrm{~N}=75 \\
\mathrm{R}^{2}=.696 \\
\end{array}$} & \multicolumn{2}{|c|}{$\begin{array}{c}\text { Model 4c } \\
\mathrm{N}=90 \\
\mathrm{R}^{2}=.567\end{array}$} \\
\hline & $b(S E)$ & $\begin{array}{c}\text { bias-corrected } \\
95 \% \mathrm{CI} \\
\end{array}$ & $b(S E)$ & $\begin{array}{c}\text { bias-corrected } \\
95 \% \text { CI } \\
\end{array}$ & $b(S E)$ & $\begin{array}{c}\text { bias-corrected } \\
95 \% \text { CI } \\
\end{array}$ \\
\hline Subjective thriving & $.182(.41)$ & {$[-.53,1.13]$} & $-.464(.426)$ & {$[-1.29, .40]$} & $.814(.354)^{*}$ & {$[.09,1.49]$} \\
\hline \multicolumn{7}{|l|}{ Cultural values } \\
\hline Power distance & $-.004(.004)$ & {$[-.01, .004]$} & $-.006(.004)$ & {$[-.01, .002]$} & & \\
\hline Individualism & $.009(.004)^{*}$ & {$[.002, .02]$} & $.005(.004)$ & {$[-.002, .01]$} & $.006(.003)$ & {$[-.0001, .01]$} \\
\hline Masculinity & $-.003(.002)$ & {$[-.01, .002]$} & $-.001(.002)$ & {$[-.01, .004]$} & & \\
\hline Uncertainty avoidance & $-.003(.003)$ & {$[-.01, .003]$} & $.00003(.003)$ & {$[-.01, .01]$} & & \\
\hline Long-term orientation & $.002(.003)$ & {$[-.005, .01]$} & $.002(.003)$ & {$[-.004, .01]$} & & \\
\hline Indulgence & $.007(.004)^{*}$ & {$[-.0004, .01]$} & $.008(.003)^{*}$ & {$[.001, .01]$} & & \\
\hline Thriving $\mathrm{x}$ Individualism & & & $.038(.013)^{* *}$ & {$[.01, .06]$} & $.035(.011)^{* *}$ & {$[.01, .06]$} \\
\hline Log GDP per capita & $.177(.165)$ & {$[-.15, .52]$} & $.206(.167)$ & {$[-.12, .53]$} & $.221(.112)^{*}$ & {$[.01, .45]$} \\
\hline Average lifespan & $-.005(.017)$ & {$[-.04, .03]$} & $-.007(.016)$ & {$[-.04, .03]$} & $-.003(.015)$ & {$[-.03, .03]$} \\
\hline Median age & $-.003(.018)$ & {$[-.04, .03]$} & $-.009(.017)$ & {$[-.04, .03]$} & $-.025(.012)^{*}$ & {$[-.05,-.003]$} \\
\hline Literacy & $-.086(.902)$ & {$[-1.93,1.66]$} & $.366(.843)$ & {$[-1.44,1.94]$} & $.004(.751)$ & {$[-1.62,1.32]$} \\
\hline Sex ratio (M:F) & $3.231(1.803)$ & {$[-.14,6.91]$} & $2.564(1.805)$ & {$[-.81,6.27]$} & $.582(.644)$ & {$[-.56,2.03]$} \\
\hline
\end{tabular}


Table 5. Regression table for model 5 assessing the indirect effects of wealth and health on altruism through SWB controlling for sociodemographic variables in sub-sample.

\begin{tabular}{|c|c|c|c|c|}
\hline & & $\begin{array}{r}\mathrm{Mo} \\
\mathrm{N}= \\
(\mathrm{Med}\end{array}$ & $\begin{array}{l}\text { el } 5 \\
90 \\
\text { ation) }\end{array}$ & \\
\hline Subjective Thriving & $b(S E)$ & $\begin{array}{c}\text { bias-corrected } \\
95 \% \text { CI }\end{array}$ & & \\
\hline Log GDP per capita & $.094(.046)^{*}$ & {$[.01, .19]$} & & \\
\hline Average lifespan & $.011(.005)^{*}$ & {$[.003, .02]$} & & \\
\hline Median age & $-.007(.004)$ & {$[-.02, .001]$} & & \\
\hline Literacy & $.064(.205)$ & {$[-.34, .48]$} & & \\
\hline Sex ratio $(M: F)$ & $.019(.246)$ & {$[-.45, .69]$} & & \\
\hline Altruism & $b(S E)$ & $\begin{array}{c}\text { bias-corrected } \\
95 \% \mathrm{CI} \\
\end{array}$ & $\begin{array}{c}\text { indirect effect } \\
\text { (SE) }\end{array}$ & $\begin{array}{c}\text { bias-corrected } \\
95 \% \text { CI } \\
\end{array}$ \\
\hline Subjective thriving & $1.608(.294)^{* * *}$ & {$[1.07,2.23]$} & & \\
\hline Log GDP per capita & $.359(.113)^{* *}$ & {$[.15, .59]$} & $.151(.08)^{*}$ & {$[.02, .33]$} \\
\hline Average lifespan & $-.014(.016)$ & {$[-.04, .02]$} & $.017(.008)^{*}$ & {$[.005, .04]$} \\
\hline Median age & $-.011(.012)$ & {$[-.03, .01]$} & $-.012(.007)$ & {$[-.03, .001]$} \\
\hline Literacy & $-1.08(.796)$ & {$[-2.79, .33]$} & $.103(.335)$ & {$[-.55, .81]$} \\
\hline Sex ratio $(M: F)$ & $.178(.827)$ & {$[-.68,2.31]$} & $.03(.39)$ & {$[-.73,1.09]$} \\
\hline
\end{tabular}


Table 6. Regression table for model 6 assessing the indirect effects of wealth and health on altruism through SWB across varying levels of individualism controlling for sociodemographic variables.

\begin{tabular}{|c|c|c|c|c|}
\hline \multirow[b]{2}{*}{ Subjective Thriving } & \multicolumn{4}{|c|}{$\begin{array}{c}\text { Model } 6 \\
\mathrm{~N}=90 \\
\text { (Moderated Mediation) }\end{array}$} \\
\hline & $b(S E)$ & $\begin{array}{c}\text { bias-corrected } \\
95 \% \mathrm{CI}\end{array}$ & & \\
\hline Log GDP per capita & $.094(.046)^{*}$ & {$[.01, .19]$} & & \\
\hline Average lifespan & $.011(.005)^{*}$ & {$[.003, .02]$} & & \\
\hline Median age & $-.007(.004)$ & {$[-.02, .001]$} & & \\
\hline Literacy & $.064(.205)$ & {$[-.34, .48]$} & & \\
\hline Sex ratio (M:F) & $.019(.246)$ & {$[-.45, .69]$} & & \\
\hline Altruism & $b(S E)$ & $\begin{array}{c}\text { bias-corrected } \\
95 \% \mathrm{CI}\end{array}$ & $\begin{array}{c}\text { indirect effect } \\
\text { (SE) }\end{array}$ & $\begin{array}{c}\text { bias-corrected } \\
95 \% \mathrm{CI}\end{array}$ \\
\hline Subjective thriving & $.814(.354)^{*}$ & {$[.09,1.49]$} & & \\
\hline Individualism & $.006(.003)$ & {$[-.0001, .01]$} & & \\
\hline Thriving x Individualism & $.035(.011)^{* *}$ & {$[.01, .06]$} & & \\
\hline Log GDP per capita & $.221(.112)^{*}$ & {$[.01, .45]$} & $\begin{array}{c}.076(.052) \\
\text { conditional }^{\wedge}\end{array}$ & {$[.004, .22]$} \\
\hline Average lifespan & $-.003(.015)$ & {$[-.03, .03]$} & $\begin{array}{c}.009(.006) \\
\text { conditional }^{\wedge}\end{array}$ & {$[.001, .02]$} \\
\hline Median age & $-.025(.012)^{*}$ & {$[-.05,-.003]$} & $-.006(.005)$ & {$[-.02, .0002]$} \\
\hline Literacy & $.004(.751)$ & {$[-1.62,1.32]$} & $.052(.185)$ & {$[-.24, .55]$} \\
\hline Sex ratio (M:F) & $.582(.644)$ & {$[-.56,2.03]$} & $.015(.209)$ & {$[-.33, .63]$} \\
\hline
\end{tabular}

Note. Standard errors (SE) and confidence intervals (CI) are bias-corrected using 5000 bootstrap resamples; 'See Table 7 for conditional indirect effects on altruism through subjective thriving; ${ }^{* * *} \mathrm{p}<.001,{ }^{* *} \mathrm{p}<.01,{ }^{*} \mathrm{p}<.05$ 
Table 7. Indirect effects of wealth (log GDP) and health (average lifespan) on altruism through thriving across levels of individualism.

\begin{tabular}{ccccc}
\hline Predictor & $\begin{array}{c}\text { Levels of } \\
\text { Individualism }\end{array}$ & $\begin{array}{c}\text { Conditional } \\
\text { indirect effect }\end{array}$ & Standard Error & $\begin{array}{c}\text { bias-corrected } \\
\text { 95\% CI }\end{array}$ \\
\hline \multirow{4}{*}{$\begin{array}{c}\text { Log GDP per } \\
\text { capita }\end{array}$} & Mean $-1 \mathrm{SD}$ & .004 & .056 & {$[-.11, .12]$} \\
& Mean $-.5 \mathrm{SD}$ & .040 & .050 & {$[-.03, .18]$} \\
& Mean $+.5 \mathrm{SD}$ & $.076^{*}$ & .052 & {$[.004, .22]$} \\
& Mean + 1 SD & $.113^{*}$ & .062 & {$[.02, .27]$} \\
\hline \multirow{4}{*}{$\begin{array}{c}\text { Average } \\
\text { lifespan }\end{array}$} & Mean $-1 \mathrm{SD}$ & .0005 & .076 & {$[.02, .33]$} \\
& Mean $-.5 \mathrm{SD}$ & .005 & .007 & {$[-.01, .01]$} \\
& Mean & $.009^{*}$ & .006 & {$[-.005, .02]$} \\
& Mean +.5 SD & $.013^{*}$ & .006 & {$[.001, .02]$} \\
& Mean + 1 SD & $.017^{*}$ & .006 & {$[.003, .03]$} \\
\hline
\end{tabular}

Note. Standard errors (SE) and confidence intervals (CI) are bias-corrected using 5000 bootstrap resamples; "indicates bias-corrected $95 \%$ confidence intervals for indirect effect sizes excluding zero. 
Figure 1. Associations of subjective well-being (x-axis) with altruistic variables (y-axis), pairwise excluding countries without both altruism and well-being data.

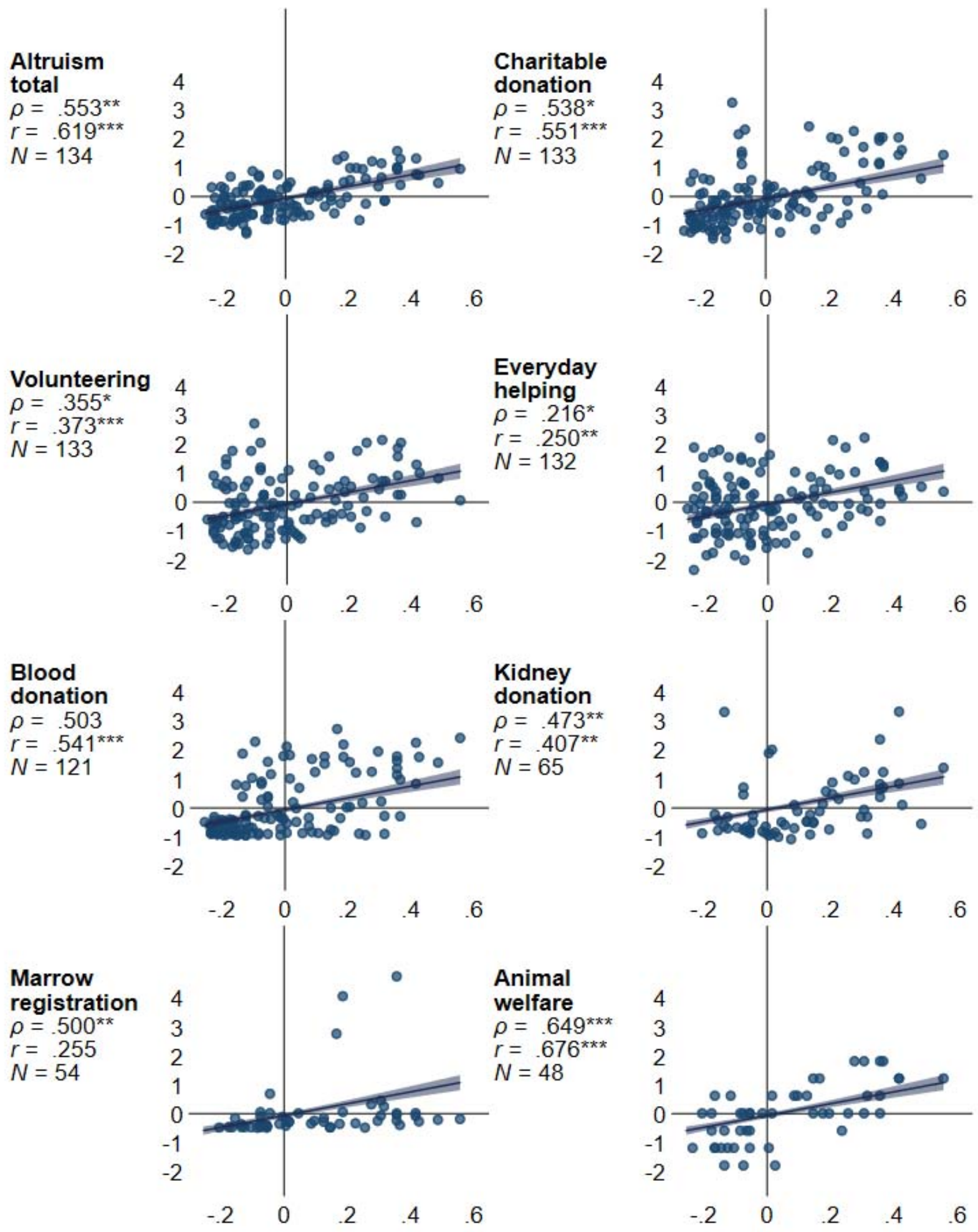


Figure 2. Marginal plot of subjective well-being $\mathrm{x}$ individualism interaction effect on altruism, controlling for log GDP, median age average lifespan, literacy, and sex ratio.

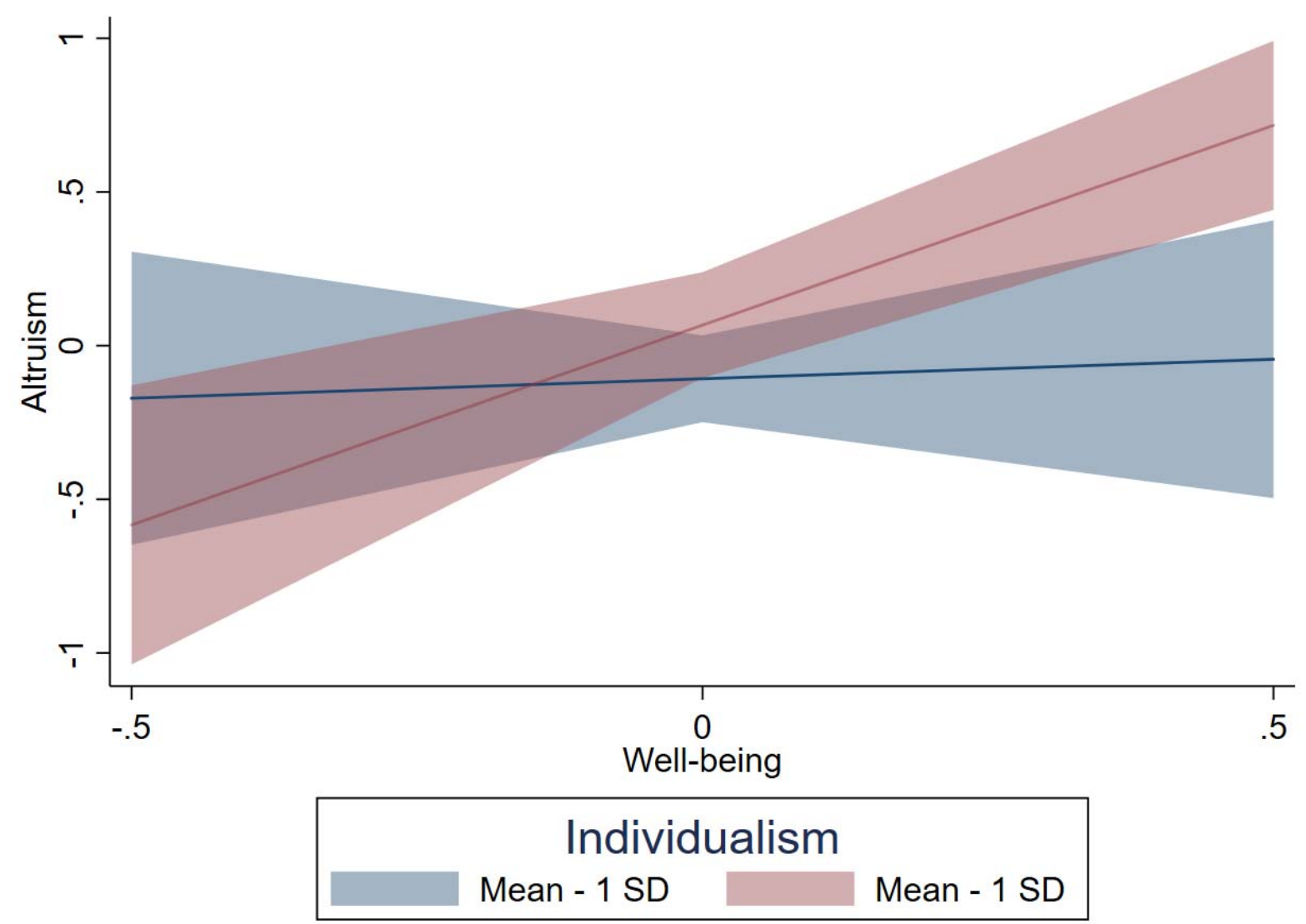


Figure 3a-e. Geographic distribution of average altruism, subjective thriving (well-being), individualism, average lifespan, and GDP (per capital). Gray color indicates missing data. All data are z-scored.

\section{Altruism by Country}

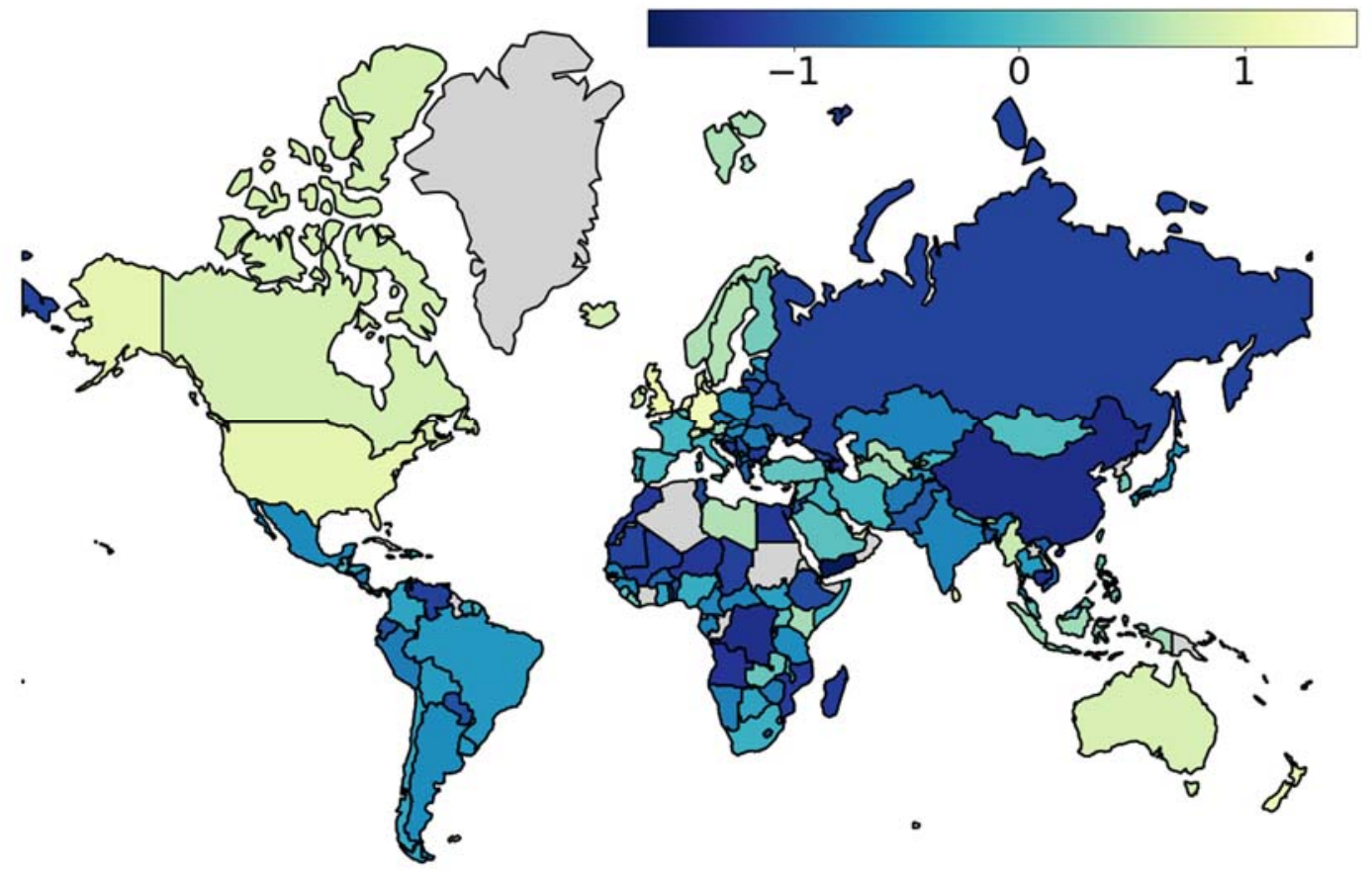

Well-being (Thriving) by Country

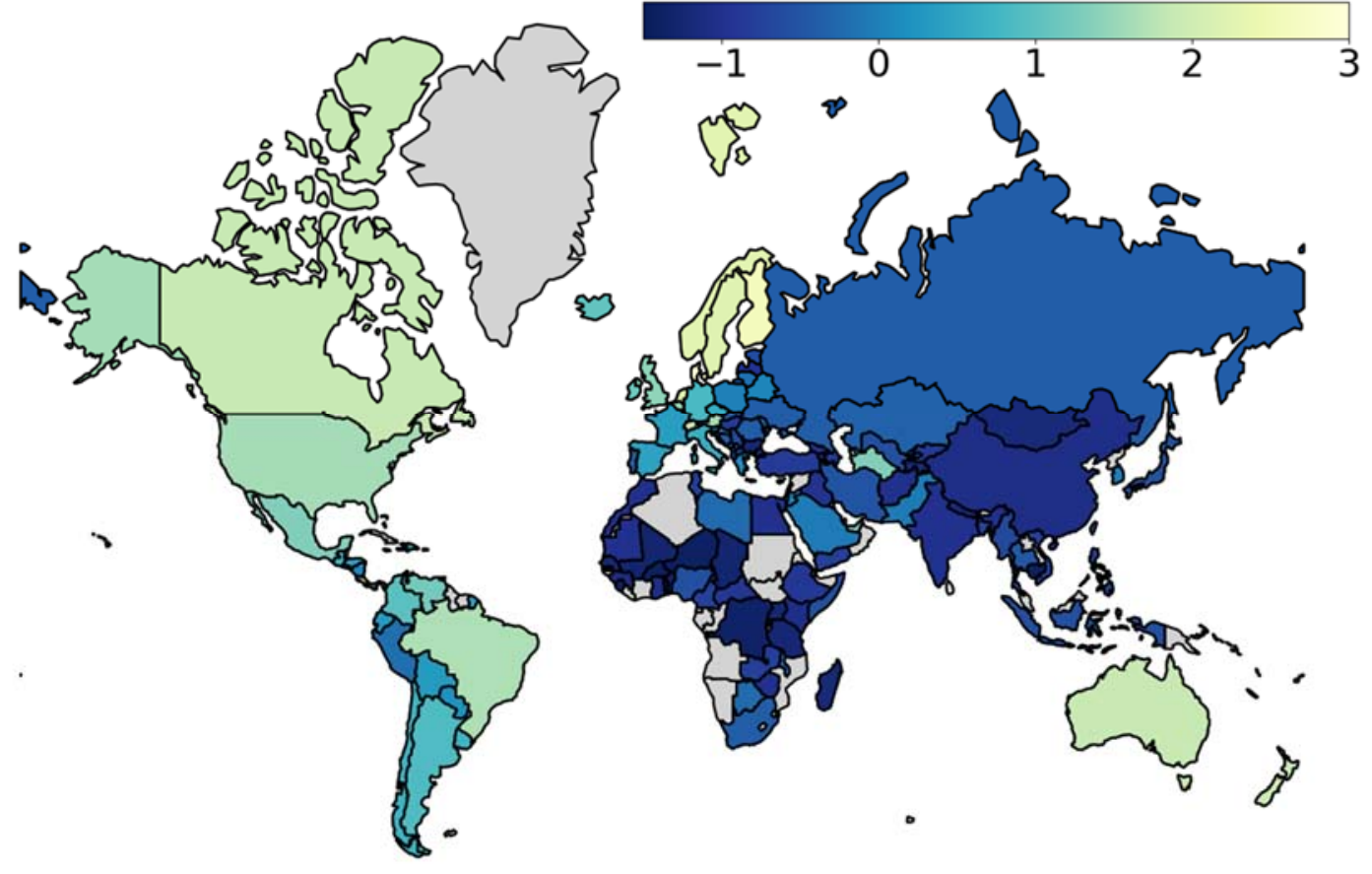




\section{Individualism by Country}

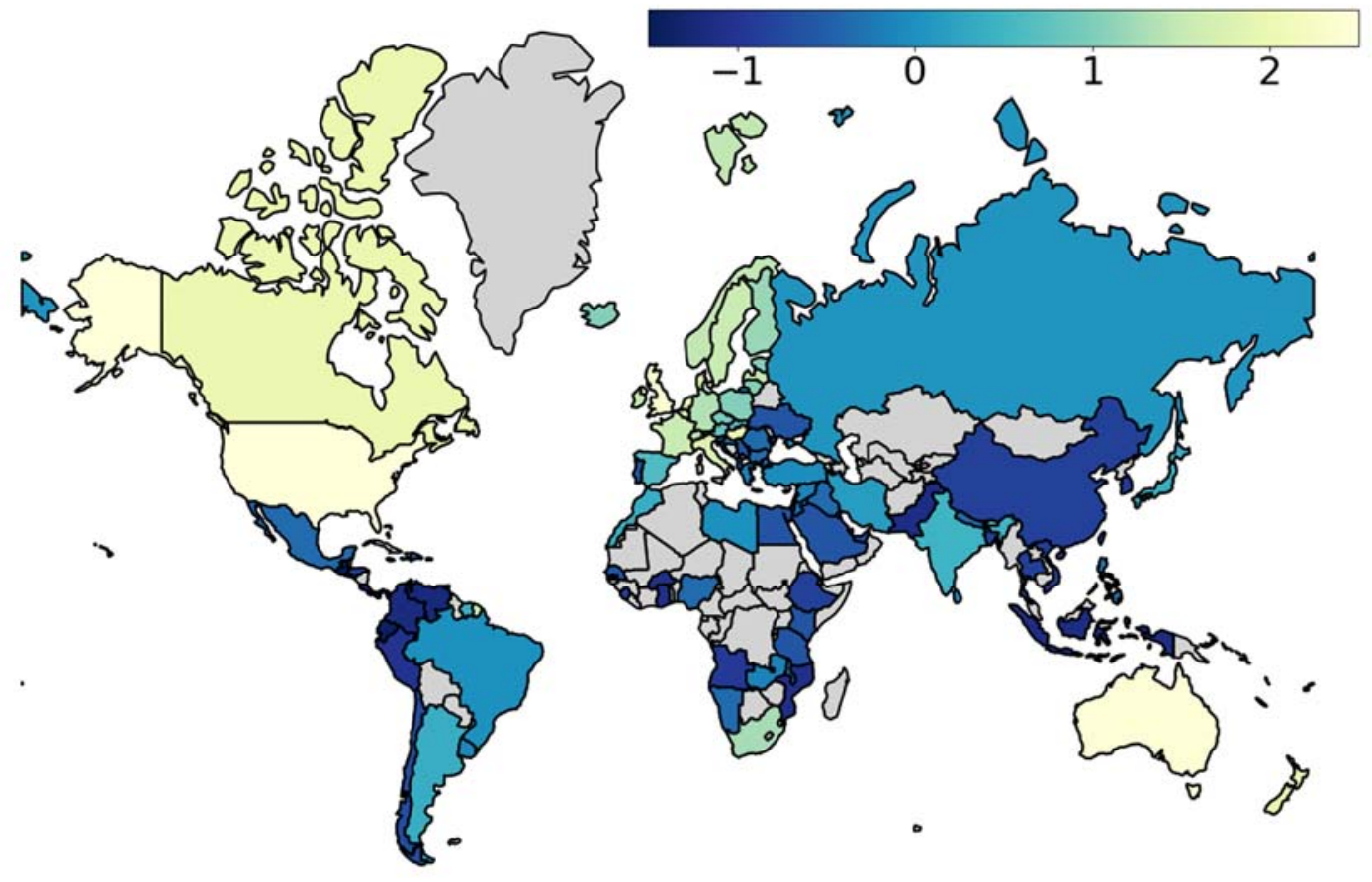

\section{Average Lifespan by Country}

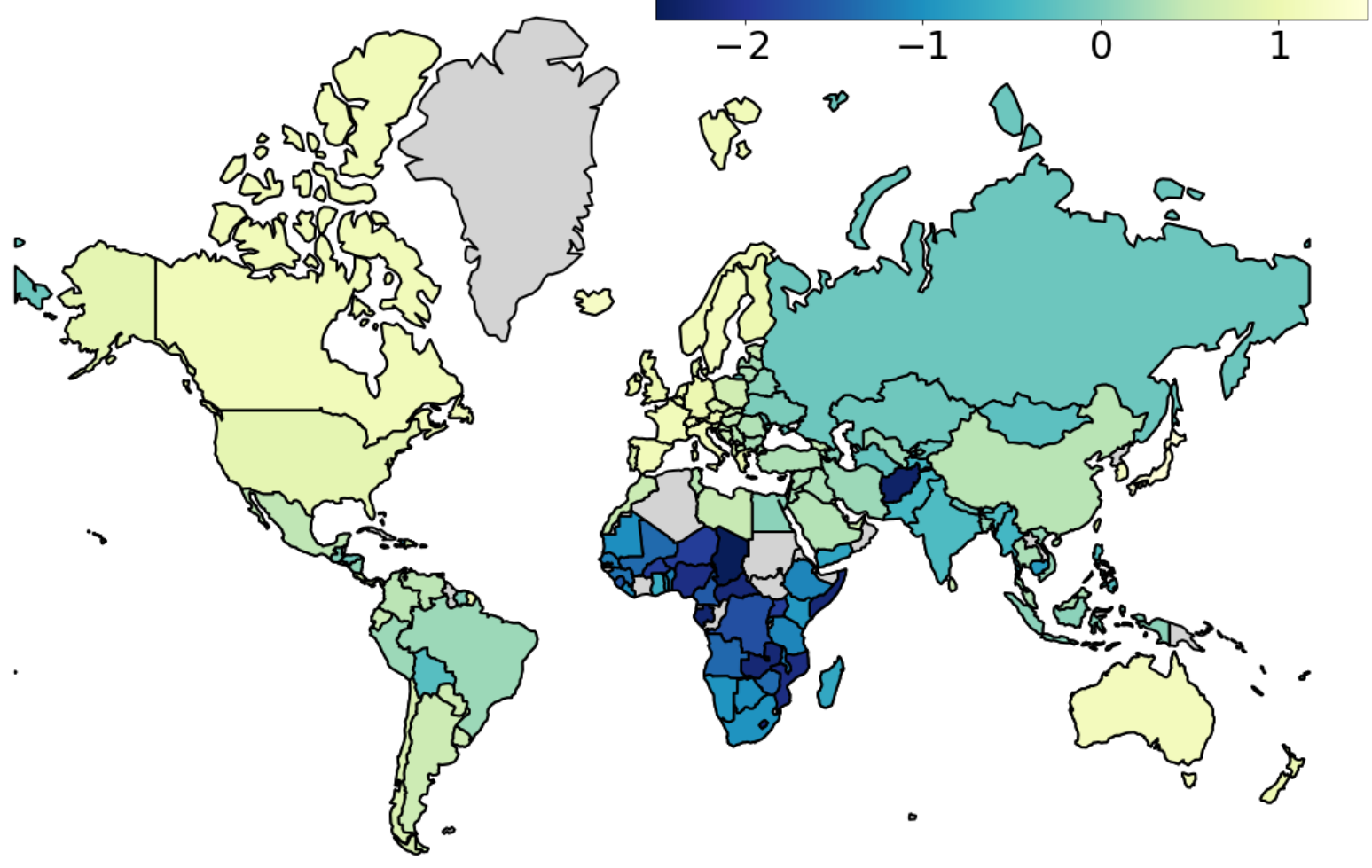




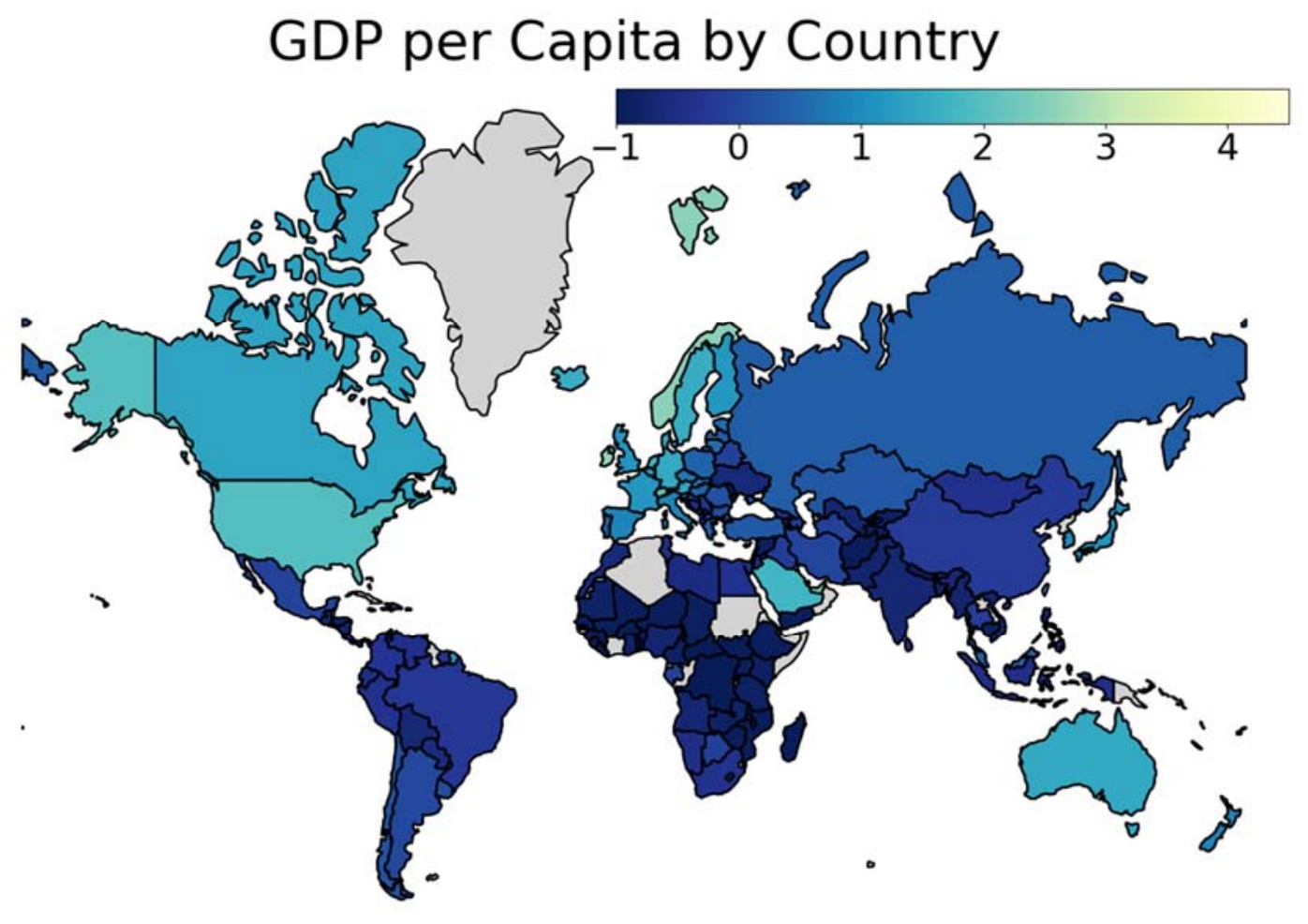

